\title{
Impact of Innovation on the Economic Efficiency of Power Engineering Enterprises: Assessment of Interdependence
}

\author{
Elena Rytova ${ }^{1}$, Polina Osyka ${ }^{1}$, Natalia Victorova ${ }^{1 *}$ \\ ${ }^{1}$ Peter the Great St. Petersburg Polytechnic University, Polytechnicheskaya Street, 29, St. Petersburg, 195251, \\ Russia
}

\begin{abstract}
This paper assesses the impact of intangible assets on the economic efficiency of an enterprise, considering the power engineering industry as a subject of research. This study aims to assess the influence of individual factors typical of innovation activity in power engineering industries on an enterprise's performance. In order to do so, both absolute and relative indicators were selected. Conducted on the basis of the Emerging Market Information Service (EMIS) financial statements, this paper provides an analysis and assessment of 159 observations for the period 2017-2019. Correlation and regression analyses were applied as the main research method. The Stata software package served as the primary research platform. Issues such as the potential of energy engineering and development prospects for the industry are currently widely discussed. In this regard, the main goal and topic of this study are relevant. The scientific validity of this paper is established based on the following elements of this study: the sample of analyzed enterprises, the comprehensive range of indicators engaged in modeling, and the obtained results and their scientific interpretation. This paper provides three models that reflect the dependence of return on capital on the indicators of intangible assets, goodwill, and book value. Furthermore, an alternative model was designed to assess the influence of the same factors on the resulting net profit indicator. A comparative analysis of the obtained models was conducted. A regression model built using the least squares method was chosen.
\end{abstract}

Keywords: Digital tools; Econometric model; Intangible assets; Innovation (activity); Power engineering

\section{Introduction}

An unstable external environment raises numerous problems related to effective management in an enterprise. One of the main factors contributing to this process is the development of modern information and telecommunications technologies and other technological innovations. Drivers, such as innovative activity and the level of investment allocated to technological development, play a key role in terms of sustainable strategic development (Rudskaya and Rodionov, 2017). At present, enterprises are experiencing a complete transformation of management architecture, creating new types of response to internal and external challenges. These processes are accelerated by the digitalization of the economy and the desire of enterprises to introduce innovation via the broadening range of the latest digital tools used in the analysis of financial information and production management (Balashova and Gromova, 2017). 
In the new era of industrial development, the ratio of enterprise assets to intangible assets is inevitably shifting, and the importance of R\&D is growing (Berawi, 2021; Yuan et al., 2021). Moreover, it is important to ensure a fair assessment of the intellectual capital level of each individual economic entity; however, at the moment, there is no universal method for this. This increases the relevance of research on new methods of intellectual capital assessment and their comparison with existing methods (Zaytsev et al., 2020).

This is particularly relevant for the energy engineering industry, where digitalization and innovation are the key agents in maintaining competitiveness in the market. In this regard, the R\&D intensity has been highlighted by many researchers, whose works are briefly reviewed in this paper. Various authors confirm the relevance of studying the specifics of power engineering and its development prospects in this regard. In particular, Langmaak et al. (2013) designed a model for estimating the cost of equipment in power engineering enterprises. Okedu et al. (2021) studied the economic efficiency of modernized equipment, and Babak et al. (2021) provided examples of models aimed at monitoring and diagnostics of electric power facilities, which directly affect the innovation activity of an enterprise and its financial efficiency. Research has mainly studied the efficiency of innovative equipment used in the production process. Such models include equipment indicators, such as electricity consumption (Wang et al., 2013), equipment failure cases (Wang and Li, 2021), and units' technical characteristics (Babak et al., 2021), but not the innovation impact on the financial result of an enterprise as an economic entity. Assessment of the impact of innovation on the economic efficiency of power engineering enterprises has not been sufficiently covered, especially regarding the methods of mathematical modeling that are applied. This lack of research emphasizes the particular relevance of this paper, which takes the financial result as the resulting indicator, expressed through the turnover of the enterprise's capital and net profit within the framework of this research work.

\section{Literature Review}

Planning expenses and increasing profitability are significant in terms of maintaining the stable financial activity of an enterprise. The COVID-19 pandemic was a precedent to prove that via its effect on both the value of shares on the stock market (Neslihanoglu, 2021) and the profitability and volatility of renewable energy sources (Liu et al., 2021). The pandemic has had a significant impact not only on individual business sectors, but also on entire regions (Rodionov et al., 2021). As Liu et al. (2021) pointed out, the impact of the economic uncertainty caused by the pandemic turned out to be more significant than the impact of the global financial crisis. Many other researchers have focused their work on the consequences of COVID-19, including Xiao et al. (2021), who considered the pandemic in terms of its influence on the financial market. In turn, Salisu and Obiora (2021) evaluated the effectiveness of hedging financial innovations both before and during the pandemic, showing that industry innovations provide sustainable investment opportunities. This situation is also relevant to the power engineering industry, which has been deeply affected by the pandemic, due to the fact that the industry is characterized by a high degree of $R \& D$ intensity (Okedu et al., 2021).

The challenge of assessing the impact of digitalization and R\&D intensity on financial efficiency can be met via modeling methods. Modeling can return rather ambiguous and even unexpected results, both when analyzing the financial activity of an enterprise at the micro level (Victorova et al., 2020) and the development of regions at the macro level (Berawi, 2016; Rytova et al., 2020; Skhvediani and Sosnovskikh, 2020). Using mathematical tools, Langmaak et al. (2013) designed several models of production costs in order to 
optimize the production process.

It is worth pointing out that the most accurate forecasting can be achieved through the analysis of non-financial data, news reports, and social networks, which is currently being actively implemented through AI technologies (Thiele, 2021) and software programs (Barykin et al., 2020).

The use of digital products in the process of enterprise management is yet another issue raised by most researchers. Digital tools enable enterprises to respond quickly to changes in financial flows by regulating and expenses (Nyman et al., 2021). As already stated, power engineering is characterized by a fairly high R\&D intensity (Wang and Li, 2021). Balashov (2020) highlighted the importance of investments in R\&D and the modernization of equipment in order to both maintain competitiveness in the market and increase equipment efficiency. Ulrich and Lehr (2020) and Trotta (2020) assessed the impact of innovations on the environment and the environmental friendliness of industrial development. Currently, Russian enterprises are experiencing high competition due to a technological backlog, especially in terms of equipment and materials (Balashov, 2020). In this regard, one of the top priorities is to build a policy of accelerated development in industrial technologies and boost the scientific and technological potential of enterprises (Lozenko and Boldyrev, 2019). Despite being immensely widespread, statements on the obvious scientific and technological lag of Russian enterprises require the confirmed results of quantitative analysis.

Thus, based on the results and conclusions obtained from the research framework of other scientists, two hypotheses can be put forward: (1) due to the fact that the economic efficiency of a power engineering enterprise is significantly influenced by the indicators of goodwill and intangible assets, the industry itself is characterized by a high degree of innovation activity and digitalization; and (2) the factor of innovation activity will be indirectly expressed through the main production assets and the book value of an enterprise, since these assets are typical of the industry and, what is more, the innovative status of an enterprise depends on them.

\section{Methods}

The development of a regression model and the selection of factors should take into account the specifics of the given industry. Fifty-three Russian power engineering enterprises were selected as the research subjects. Financial information on the presented enterprises was collected based on the information available in the Emerging Market Information Service (EMIS) system for the period from 2017 to 2019. The total number of observations carried out was 159 . The factors listed in Table 1 were selected for the model. The novelty of the study is an assessment of the impact of the introduction of innovative technologies from a financial point of view rather than an assessment of the efficiency of the production process. All factors were taken from the EMIS database. The authors assume that the impact of innovation potential and digitalization will be indirectly expressed through the following variables associated with the intangible assets of the enterprise: Intangible assets and goodwill, Book Value, Book value of an enterprise (trend), and Basic production assets. In this study, the authors proceed from the assumption that R\&D costs are included in Intangible assets and goodwill.

The choice of factors is justified by the following considerations: Profitability of the capital employed and the net profit characterize the economic efficiency of an enterprise. Revenue reflects the demand for products in the market, represented by the income obtained from sales. Another predictor chosen was total income. This choice is based on the assumption that total income also includes income from other types of enterprise activities 
(for example, the provision of related services, such as turbine repairs and cleaning), which also require cutting-edge equipment.

Table 1 Original model specification (compiled by the authors, data source: EMIS database https://www.emis.com)

\begin{tabular}{clll}
\hline Factor & \multicolumn{1}{c}{ Name of factor } & Units & \multicolumn{1}{c}{ Factor code } \\
\hline Y & Return on capital employed & $\%$ & Return on Capital Employed \\
Y & Net profit & Million dollars & Net Profit (Loss) for the Period \\
X1 & Total operating revenue & Million dollars & Total operating revenue \\
X2 & Intangible assets and goodwill & Million dollars & Intangible assets and goodwill \\
X3 & Basic production assets & Million dollars & PropertyplantandEquipment \\
X4 & Comprehensive income & Million dollars & Comprehensive income \\
X5 & Debt & Million dollars & Debt \\
X6 & Book value & Million dollars & BookValue \\
X7 & Book value of an enterprise (trend) & $\%$ & BookValue Trend \\
X8 & Total liabilities & Million dollars & Total liabilities \\
X9 & Inventory turnover & $\%$ & Inventory Turnover \\
X10 & Current asset turnover & $\%$ & Current Asset Turnover \\
X11 & Non-current asset turnover & $\%$ & Non-current Asset Turnover \\
X12 & Cash and cash equivalents & Million dollars & Cash and Cash Equivalents \\
X13 & Total assets & Million dollars & Total assets \\
\hline
\end{tabular}

The indicators that characterize the assets of an enterprise were also selected, including intangible assets and goodwill, Basic production assets and the book value of an enterprise (absolute indicator and trend). These predictors form the foundation of the model because they represent the basis of innovation activity. In addition, the degree of their influence on the resulting indicator is capable of confirming or disproving the hypotheses that have been put forward. The turnover coefficients of stocks, as well as the current and non-current assets, reflect the efficiency of using the resources available to an enterprise, while the capital possessed manifests the ability of an enterprise to quickly acquire certain innovative assets. Debt and liabilities are also important for the model, since they have a direct impact on profit and also reflect the effectiveness of accounting and financial management. Total assets of an enterprise are another factor included in the model because this item on the balance sheet may include other types of assets, for example, those that are not classified into such analytical groups as intangible assets or fixed assets but are still important for an enterprise and have a direct impact on the financial result.

The model was designed using the Stata software package. The resultant correlation matrix shows a high dependence between a number of variables, in particular between BookValue and PropertyplantandEquipment, as well as between NetProfit (Loss) and BookValue of an enterprise. However, a negative correlation between some variables was also recorded. For instance, Intangible assets and goodwill has a negative correlation with Net Profit (Loss) for the Period and Return on Capital Employed, which are both resultant indicators in the models. This fact should be studied in more detail in the modeling process. The factors for modeling were grouped according to the results of the correlation matrix.

\section{Results and Discussion}

Several models were designed: pooled regression (ordinary least squares) (PR), fixed effects (FE), and random effects (RE) (Table 2). After iterating the models, the main significant factors that influence return on capital employed were determined: intangible assets and book value. The multicollinearity test (mean variance inflation factor $=1$ ) proves that the predictors do not have a strong correlation with each other. The PR model is significant, and this regression can be analyzed further. Nevertheless, considering the fact 
that the objects of observation are quite heterogeneous, it can be assumed that the properties of each particular object contribute to the displacement of variables. Therefore, the FE model was constructed (Table 2). The errors were poorly correlated with the repressors in the model, correlation $=0.003$. Due to the differences between the panels, the variance takes place of $(\rho=0.21)$. In general, the FE model proved to be significant as well. The F-test showed that the PR model is better suited for describing data, $F(39,69)=0.75$, $p=0.83$. In accordance with the results, the FE model was rejected. The best results were demonstrated by the RE model (Table 2). Since the relationship between Intangible assets and goodwill and Return on Capital Employed was nonlinear, the factor was logarithmed and called «LnIntangible».

Table 2 Regression analysis

\begin{tabular}{|c|c|c|c|}
\hline Name of factor & Pooled & Fixed & Random \\
\hline LnIntangible & $\begin{array}{l}-6.511^{*} \\
(2.835)\end{array}$ & $\begin{array}{l}-6.572 \\
(15.28)\end{array}$ & $\begin{array}{l}-6.511^{*} \\
(2.835)\end{array}$ \\
\hline BookValue Trend (\%) & $\begin{array}{l}-0.192^{* *} \\
(0.0222)\end{array}$ & $\begin{array}{l}-0.192^{* *} \\
(0.0283)\end{array}$ & $\begin{array}{l}-0.192^{* *} \\
(0.0222)\end{array}$ \\
\hline Constant & $\begin{array}{l}-3.079 \\
(8.195)\end{array}$ & $\begin{array}{l}-3.168 \\
(22.42)\end{array}$ & $\begin{array}{l}-3.079 \\
(8.195)\end{array}$ \\
\hline Observations & 111 & 111 & 111 \\
\hline $\mathrm{R}^{2}$ & 0.433 & 0.404 & \\
\hline Adjusted R2 & 0.423 & 0.050 & \\
\hline \multicolumn{2}{|c|}{ Standard errors in parentheses } & \multicolumn{2}{|c|}{${ }^{*} p<0.05,{ }^{* *} p<0.0001$} \\
\hline
\end{tabular}

The Hausman test for choosing between the FE and RE models also highlights the reliability of the RE model $\left(p>\chi^{2}=0.999\right)$. Thus, based on the results obtained, it can be concluded that the differences between the panels are random and errors are not correlated with predictors. In order to choose between the RE and PR models, the BreuschPagan test was used. The null hypothesis of the test is that the differences between spatial objects are zero (i.e., there is no panel data effect). The null hypothesis could not be rejected $\left(\mathrm{p}>\chi^{2}=1.00\right)$, which means that the RE model should be rejected. This results in the conclusion that the PR model describes the data better than the RE model.

Thus, a regression model that showed the highest coefficient of determination was chosen (Table 2, PR model). The linear regression equation was as follows:

$$
Y=-6.511 X_{1}-0.192 X_{2}-3.079
$$

An alternative model was also designed. In this case, the model considered the influence of several factors on another resulting indicator reflecting economic efficiency: the net profit. This time, in the given set of factors, the FE model showed the best results (Table 3). Here, we observe the dependence of net profit on book value, fixed assets (PropertyplantandEquipment), intangible assets, and receivables. Moreover, it is worth noting that the factor responsible for intangible assets in this model is generally not significant. Therefore, intangible assets were not considered in the model (Table 3). Demonstrating the best result, the alternative model justifies the influence of book value and fixed assets (PropertyplantandEquipment), thereby proving the following hypothesis: the financial result of an enterprise is influenced by innovations and equipment modernization.

Following the successful assessment of alternative models, a set of equations was obtained (Table 4), with the regression model highlighted (more relevant). It was these models that were selected according to the simulation results as the most significant. 
Table 3 The results of regression analysis: FE regression including and excluding the Intelligent assets and goodwill factor

\begin{tabular}{lcc}
\hline Model variables and parameters & $\begin{array}{c}\text { Fixed effects (FE) } \\
\text { model }\end{array}$ & $\begin{array}{c}\text { FE model excluding the Intelligent assets } \\
\text { and goodwill factor }\end{array}$ \\
\hline BookValueBV & $0.0780075^{* *}$ & $0.0783659^{* *}$ \\
PropertyplantandEquipment & $-0.0929973^{* *}$ & $-0.0945142^{* *}$ \\
Debt & $-0.0878219^{*}$ & $-0.0879602^{*}$ \\
LnIntangible & -0.089579 & 2.8238 \\
Constant & 2.7285 & 280 \\
\hline
\end{tabular}

${ }^{*} p<0.05,{ }^{* *} p<0.0001$

Table 4 Model outputs

\begin{tabular}{cccc}
\hline Y (ReturnInCapital) & $\mathrm{X}_{1}$ (LnIntangible) & $\mathrm{X}_{2}$ (BookValue Trend) & \\
\hline Regression model (PR model) & -6.511 & -0.192 & \\
Fixed effects (FE) model & -6.572 & -0.192 & \\
Random effects model & -6.511 & -0.192 & $\mathrm{X}_{3}$ (Debt) \\
\hline Y (NetProfit) & $\mathrm{X}_{1}$ (BookValue) & $\mathrm{X}_{2}$ (PropertyplantandEquipment) & -0.088 \\
\hline Alternative model (with FE) & 0.0783 & -0.09451 & -
\end{tabular}

The results obtained from the research only partially confirmed the first hypothesis, which is as follows: the economic efficiency of a power engineering enterprise is significantly influenced by the indicators of goodwill and intangible assets. However, the results may be debatable because, first, the predictor of intangible assets in all models has a marginal significance coefficient, and second, in the alternative model, it did not prove to be significant at all. In this regard, it would be logical to conclude that there is a poor correlation between intangible assets and net profit, but it is not high enough to serve as a decisive factor within the models. Perhaps the return on capital indicator is more closely related to the technological factors of the enterprise, and therefore, its connection with intangible assets is more intense. At the same time, the net profit is more responsive to implemented innovative technological solutions, which are expressed in the PropertyplantandEquipment indicator.

However, according to the models, the book value and based production assets are highly significant, which confirms the second hypothesis, which is as follows: the factor of innovation activity will be indirectly expressed through the main production assets and the book value of an enterprise. According to this obtained result, we assume the second hypothesis to be the more reliable one. Surprisingly, all models managed to show an inverse relationship between the factor of intangible assets and the resulting indicator. On the one hand, this situation seems to be quite reasonable because the more that free funds are allocated in the development of intangible assets and R\&D, the lower the net profit obtained. On the other hand, this result disproves the hypothesis on the correlation between enhancing technologies and increasing economic efficiency. Nonetheless, the results suggest that the second hypothesis can also be confirmed by the alternative model, which showed a positive trend in the correlation between the net profit and the book value of the enterprise. All the above-mentioned observations indirectly indicate the innovative nature of a company's activities, while the Intelligent assets and goodwill factor is exclusively financial. Therefore, it is obvious that an increase in R\&D costs results in a decrease in net profit.

Another essential point to consider is that not all the data were included in the sample, but only those enterprises that provided complete data. In this regard, despite its high quality and significance, the model reflects only a part of the market (about $40 \%$ of observations on the selected factors were complete) and refers only to the industry of the 
Russian Federation within the three-year span. A limited share of the enterprises observed is connected to the selected factors being specific and it not being possible to obtain open data for all enterprises within the Russian Federation.

It should be noted that the results of this study are partially confirmed by the works of other authors. In particular, Rykova et al. (2016) built a regression model of the influence of assets on production cost (the range of assets included fixed assets, intangible assets, and other types of property). The authors suggested that "the choice of the assets composition and formation of their specific weight in the structure of the balance sheet will have a significantly positive impact on achieving the target net profit in industrial organizations" (Rykova et al., 2016); their results are peculiar, however, as they are not directly connected to the power engineering industry. Yakovleva and Demidenko (2014) addressed the impact of intangible assets and R\&D on enterprise performance; the authors also discussed the problem of developing a range of tools aimed at assessing the economic efficiency of R\&D costs, and the interdependence between innovation and the financial results of an enterprise. The same problem is also discussed by Sazonov et al. (2018), who stated that "the economic results of innovation have an articulated tendency to attract investments".

Relying on the assessment conducted, it is possible to conclude that the results of this study are justified, and the hypotheses put forward prove to be reasonable. Although the models showed no exceptionally high correlation between R\&D and profit, it surely does exist. The results obtained by this research method prove the importance of innovation in terms of financial planning and create a basis for continuing the research. In addition, the models obtained can be used for the planning of cash flows or for a managerial decision on equipment modernization.

\section{Conclusions}

This paper discusses the interdependence between the factors reflecting innovation within an enterprise and the indicators of its economic efficiency. Assessment was carried out by designing and building several models and the subsequent analysis of their results. Evaluation and comparison of the developed models allowed choosing a regression model considering the following factors: intangible assets, goodwill, book value, and return on capital employed. The PR model proved to be the most comprehensive and partially confirmed the first hypothesis. Another model adopted is the alternative model with FE, which includes the following factors: net profit, book value of an enterprise, fixed production assets, and accounts receivable. The alternative model with FE managed to confirm the second hypothesis. Within the framework of the study, two main hypotheses were put forward, and the second was chosen as a more comprehensive and reliable one. The assumption of the high impact of $R \& D$ and intangible assets on financial result is also proved. Although the interdependence between the factors has been established, it does not seem to be as high as expected. These results indicate that the impact of intangible assets and technical and technological development on the financial result of an enterprise is present, but still does not play a decisive role in improving economic efficiency. In this regard, this paper sets a goal for the further expansion of the study in order to assess the degree of the $R \& D$ influence on the profit in terms of the global trends, and to draw a conclusion about the role of intellectual property in the development of the Russian power engineering industry. Further research on positive global experience in the given industry is planned, such as in China and EU countries. 


\section{Acknowledgements}

The research is partially funded by the Ministry of Science and Higher Education of the Russian Federation under the strategic academic leadership program 'Priority 2030' (Agreement 075-15-2021-1333 dated September 30, 2021).

\section{References}

Babak, V.P., Babak, S.V., Eremenko, V.S., Kuts, Y.V., Myslovych, M.V., Scherbak, L.M., Zaporozhets, A.O., 2021. Models and Measures for the Diagnosis of Electric Power Equipment. Studies in Systems, Decision and Control, Volume 360, pp. 99-126

Balashov, M.M., 2020. Import Substitution in the Power Engineering Industry. Strategic Decisions and Risk Management, Volume 11(2), pp. 182-195

Balashova, E.S., Gromova, E.A., 2017. TQM as One of the Drivers of Russian Industrial Sector. Quality - Access to Success, Volume 18(159), pp. 50-53

Barykin, S.Y., Kapustina, I.V., Kirillova, T.V., Yadykin, V.K., Konnikov, Y.A., 2020. Economics of Digital Ecosystems. Journal of Open Innovation: Technology, Market, and Complexity, Volume 6(4), pp. 1-16

Berawi, M.A., 2016. Accelerating Sustainable Infrastructure Development: Assuring WellBeing and Ensuring Environmental Sustainability. International Journal of Technology, Volume 7(4), pp. 527-529

Berawi, M.A., 2021. Philosophy of Technology Design: Creating Innovation and Added Value. International Journal of Technology, Volume 12(3), pp. 444-447

Langmaak, S., Wiseall, S., Bru, C., Adkins, R., Scanlan, J., Sóbester, A., 2013. An activity-basedParametric Hybrid Cost Model to Estimate the Unit Cost of a Novel Gas Turbine Component. International Journal of Production Economics, Volume 142(1), pp. 74-88

Lozenko, V.K., Boldyrev, K.V., 2019. The Share of Russian Energy Machine Building Companies in the Structure of Global Installed Capacity. International Trade and Trade Policy, Volume 2, pp. 63-71

Liu, T., Nakajima, T., Hamori, S., 2021. The Impact of Economic Uncertainty Caused by COVID-19 on Renewable Energy Stocks. Empirical Economics, Volume 2021 Jun 27, pp. $1-21$

Neslihanoglu, S., 2021. Linearity Extensions of the Market Model: A Case of the Top 10 Cryptocurrency Prices during the pre-COVID-19 and COVID-19 Periods. Financial Innovation, Volume 7(38), pp. 1-27

Nyman, R., Kapadia, S., Tuckett, D., 2021. News and Narratives in Financial Systems: Exploiting Big Data for Systemic Risk Assessment. Journal of Economic Dynamics and Control, Volume 127, pp. 1-28

Okedu, K.E., Al Tobi, M., Al Araimi, S., 2021. Comparative Study of the Effects of Machine Parameters on DFIG and PMSG Variable Speed Wind Turbines During Grid Fault. Frontiers in Energy Research, Volume 9, pp. 1-13

Rodionov, D.G., Konnikov, E.A., Nasrutdinov, M.N., 2021. A Transformation of the Approach to Evaluating a Region's Investment Attractiveness as a Consequence of the COVID-19 Pandemic. Economies, Volume 9(2), pp. 1-20

Rudskaya, I., Rodionov, D., 2017. Econometric Modeling as a Tool for Evaluating the Performance of Regional Innovation Systems (with Regions of the Russian Federation as the Example). Academy of Strategic Management Journal, Volume 16(2)

Rykova, I., Korablev, D., Gubanov, R., 2016. Influence Factors of Financial Performance of Industrial Organizations Russia with Regard to the State Support of Industry Economy. Journal of Corporate Finance Research, Volume 10(2), pp. 51-69 
Rytova, E., Victorova, N., Koroleva, L., Pokrovskaia, N., 2020. Determinants of Tax Capacity for a Territory (The Case of the Russian Federal Districts). International Journal of Technology, Volume 11(6), pp. 1255-1264

Salisu, A.A., Obiora, K., 2021. COVID-19 Pandemic and the Crude Oil Market Risk: Hedging Options with Non-Energy Financial Innovations. Financial Innovation, Volume 7(34), pp. 1-19

Sazonov, A., Kolosova, V., Vnuchkov, Y., 2018. Methods of Evaluation and Analysis of the Economic Efficiency of The Innovative Activity of the Enterprise. Bulletin of the Moscow State Regional University, Economics, Volume 2, pp. 180-187

Skhvediani, A., Sosnovskikh, S., 2020. What Agglomeration Externalities Impact the Development of the Hi-tech Industry Sector? Evidence from the Russian Regions. International Journal of Technology, Volume 11(6), pp. 1091-1102

Thiele, L.P., 2021. Rise of the Centaurs: The Internet of Things Intelligence Augmentation. In: Towards an International Political Economy of Artificial Intelligence, Keskin, T., Kiggins R.D., (eds.), Palgrave Macmillan, Cham, pp. 39-61

Trotta, G., 2020. Assessing Energy Efficiency Improvements and Related Energy Security and Climate Benefits in Finland: An ex Post Multi-Sectoral Decomposition Analysis. Energy Economics, Volume 86, https://doi.org/10.1016/j.eneco.2019.104640

Ulrich, P., Lehr, U., 2020. Economic Effects of an E-Mobility Scenario-Input Structure and Energy Consumption. Economic Systems Research, Volume 32(1), pp. 84-97

Victorova, N., Otrubyannikova, P., Sokolova, S., Gorovoy, A., 2020. The Specifics of Accounting Policy Formation in Russian IT Companies. In: Proceedings of the $2^{\text {nd }}$ International Scientific Conference on Innovations in Digital Economy: SPBPU IDE2020, Article no, 58, pp. 1-8

Wang, R., Li, M., 2021. Power Equipment Fault Information Acquisition System based on Internet of Things. Eurasip Journal on Wireless Communications and Networking, Volume 2021(1), pp. 1-22

Wang, X., Yu, B., Chen, Z., Hou, L. 2013. Forecasting Modeling and Analysis of Power Engineering in China based on Semi-Parametric Regression Model. Przeglad Elektrotechniczny, Volume 89(3), pp. 161-169

Xiao, H., Xiong, X., Chen, W., 2021. Introduction to the Special Issue on Impact of COVID-19 and Cryptocurrencies on the Global Financial Market. Financial Innovation, Volume $7(27)$, pp. 1-2

Yuan, S., Musibau, H.O., Genç, S.Y., Shaheen, R., Ameen, A., Tan, Z., 2021. Digitalization of Economy is the Key Factor Behind Fourth Industrial Revolution: How G7 Countries are Overcoming with the Financing Issues? Technological Forecasting and Social Change, Volume 165, https://doi.org/10.1016/j.techfore.2020.120533

Yakovleva, E., Demidenko, D., 2014. Theory and Practice of Analyzing the Economic Efficiency of R \& D And Intellectual Property Objects. Scientific and Technical Bulletin of the St. Petersburg State Polytechnic University. Economic sciences, Volume 3(197), pp. 194-206

Zaytsev, A., Rodionov, D., Dmitriev, N., Ilchenko, S., 2020. Assessing Intellectual Capital from the Perspective of its Rental Income Performance. International Journal of Technology, Volume 11(8), pp. 1489-1498 